\title{
A 2-10 GHz GaAs MMIC opto-electronic phase detector for optical microwave signal generators
}

Bruun, Marlene; Gliese, Ulrik Bo; Petersen, Anders Kongstad; Nielsen, Torben Nørskov; Stubkjær, Kristian

Published in:

I E E E - M T T S International Microwave Symposium. Digest

Link to article, DOI:

10.1109/MWSYM.1994.335443

Publication date:

1994

Document Version

Publisher's PDF, also known as Version of record

Link back to DTU Orbit

Citation (APA):

Bruun, M., Gliese, U. B., Petersen, A. K., Nielsen, T. N., \& Stubkjær, K. (1994). A 2-10 GHz GaAs MMIC optoelectronic phase detector for optical microwave signal generators. I'E E E - M T TS International Microwave Symposium. Digest, 1, 499-502. https://doi.org/10.1109/MWSYM.1994.335443

\section{General rights}

Copyright and moral rights for the publications made accessible in the public portal are retained by the authors and/or other copyright owners and it is a condition of accessing publications that users recognise and abide by the legal requirements associated with these rights.

- Users may download and print one copy of any publication from the public portal for the purpose of private study or research.

- You may not further distribute the material or use it for any profit-making activity or commercial gain

- You may freely distribute the URL identifying the publication in the public portal 


\title{
TU4C-5
}

\section{A 2-10 GHz GaAs MMIC Opto-Electronic Phase Detector for Optical Microwave Signal Generators}

\author{
M. Bruun, U. Gliese, A.K. Petersen, T.N. Nielsen and K.E. Stubkjær \\ Center for Broadband Telecommunications, Electromagnetics Institute \\ Technical University of Denmark, Building 348, DK-2800 Lyngby, Denmark
}

\begin{abstract}
Optical transmission of microwave signals becomes increasingly important. Techniques using beat between optical carriers of semiconductor lasers are promising if efficient optical phase locked loops are realized. A highly efficient GaAs MMIC optoelectronic phase detector for a $2-10 \mathrm{GHz}$ OPLL is reported.
\end{abstract}

\section{Introduction}

Efficient techniques for optical generation of microwave signals with high spectral purity are subject to much interest because of the potential of optical microwave links. A most promising method is to utilize the beat signal between the optical carriers of wideband optical phase locked semiconductor lasers [1]-[4]. The use of semiconductor lasers as opposed to solid state lasers, such as Nd:YAG, is attractive due to their compactness and potential for monolithic optoelectronic integration. In this paper we present the results on a monolithic microwave integration of the opto-electronic $(\mathrm{O} / \mathrm{E})$ phase detector, which is one of the essential parts of optical phase locked loops (OPLLs). This is, to the best of our knowledge, the first report on integration of this type of circuit.

\section{Phase Detector Function}

As shown in Fig. 1, the OPLL microwave signal generator [4] consists of a free running transmitter

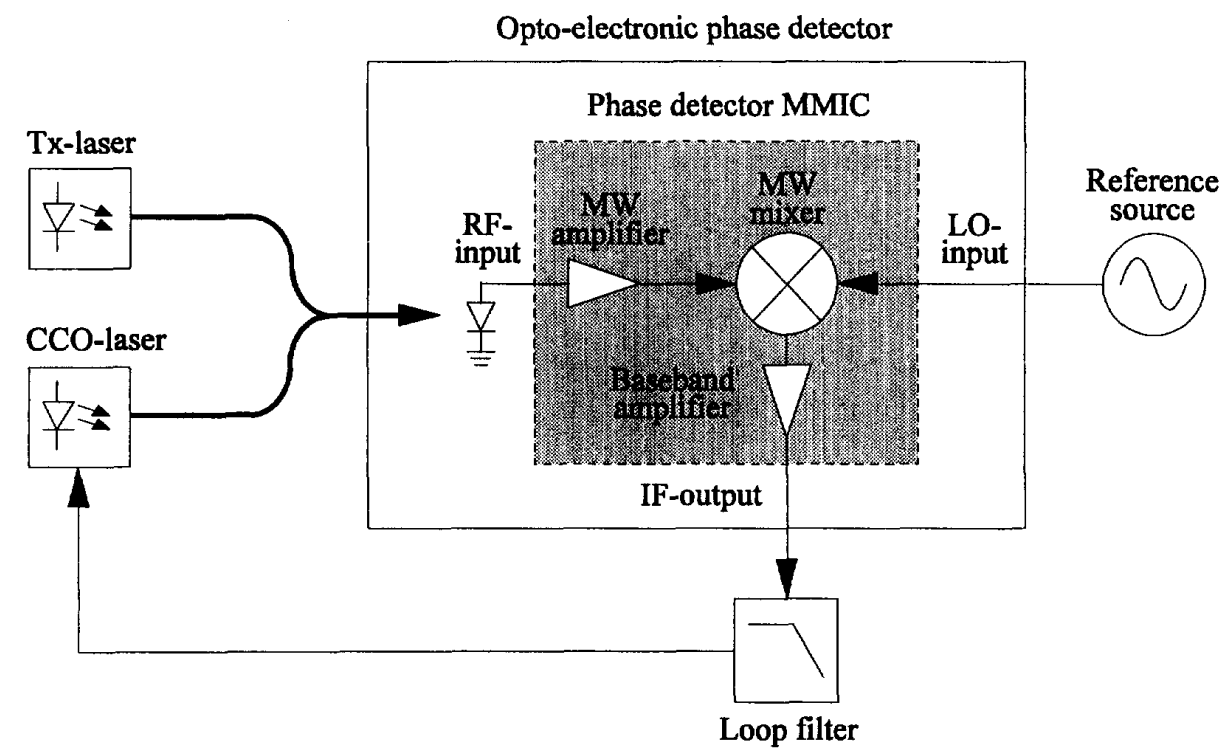

Figure 1: Schematic of the optical phase locked loop with a functional diagram for the opto-electronic phase detector MMIC. 


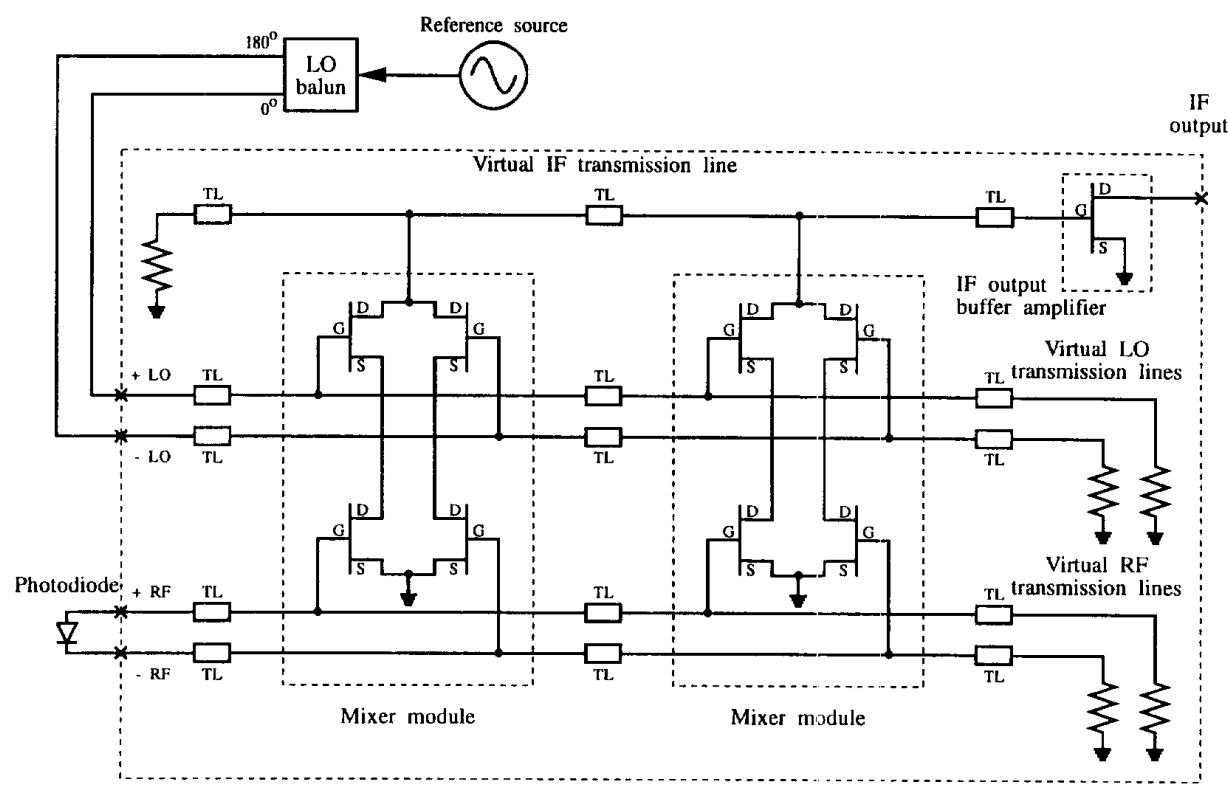

Distributed phase detector GaAs MMIC

Figure 2: Diagram of the GaAs MMIC based O/E phase detector.

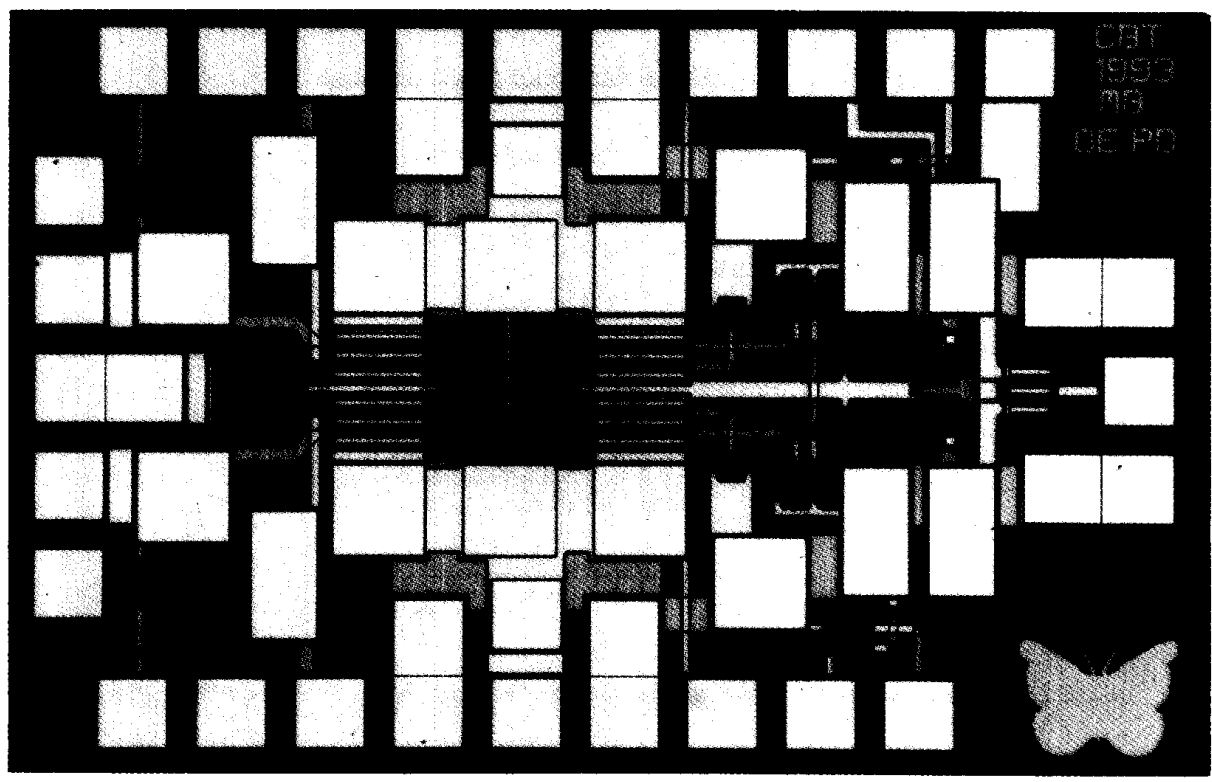

Figure 3: Photo of the phase detector GaAs MMIC having the physical dimensions of $1.1 \times 1.7 \mathrm{~mm}$. 


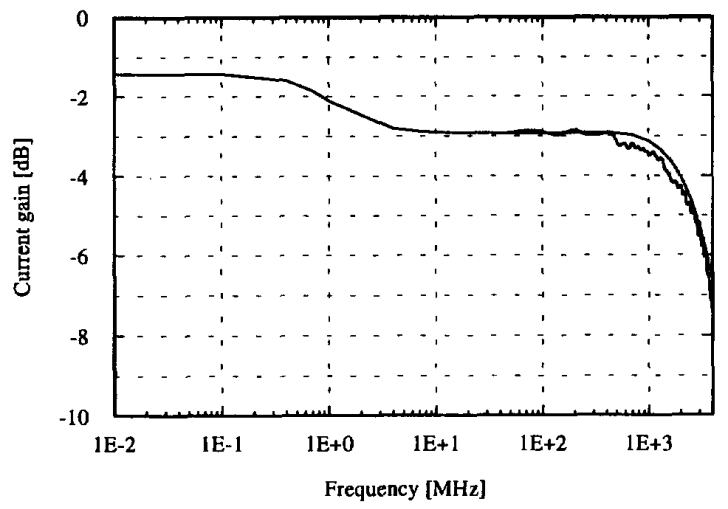

Figure 4: Current gain of the phase detector MMIC as a function of the output error signal frequency. Simulated: Smooth curve, Measured: Rippled curve. $f_{\mathrm{LO}}=8 \mathrm{GHz}, P_{\mathrm{RF}}=-35 \mathrm{dBm}$ and $P_{\text {LO }}=15 \mathrm{dBm}$.

laser (Tx-laser), an $\mathrm{O} / \mathrm{E}$ phase detector, a loop filter and a Current Controlled Oscillator laser (CCOlaser). The microwave signal that is generated by the beat of two semiconductor lasers is compared to the signal from a microwave reference source having low phase noise. The resulting phase error signal is then fed back to the CCO-laser which is forced to track the Tx-laser. This causes a significant reduction of the phase noise of the beat signal within the loop bandwidth, thereby generating an optical microwave signal with very high spectral purity [4].

The O/E phase detector measures the phase difference between two optical signals and a microwave signal as shown in Fig. 1. Functionally, it performs coherent photo-mixing followed by microwave amplification, microwave mixing and, finally, baseband amplification. The electronic parts are implemented as a GaAs monolithic microwave integrated circuit (MMIC). This is the first step towards integration of the OPLL, and it results in reduced RF-IF time delay compared to a previous bulk implementation [4]. This is essential for wideband loop operation [2].

\section{MMIC Design and Layout}

A diagram of the GaAs MMIC based O/E phase detector is shown in Fig. 2. A distributed design has been chosen to increase the overall gain and bandwidth. Double balanced signals are applied at

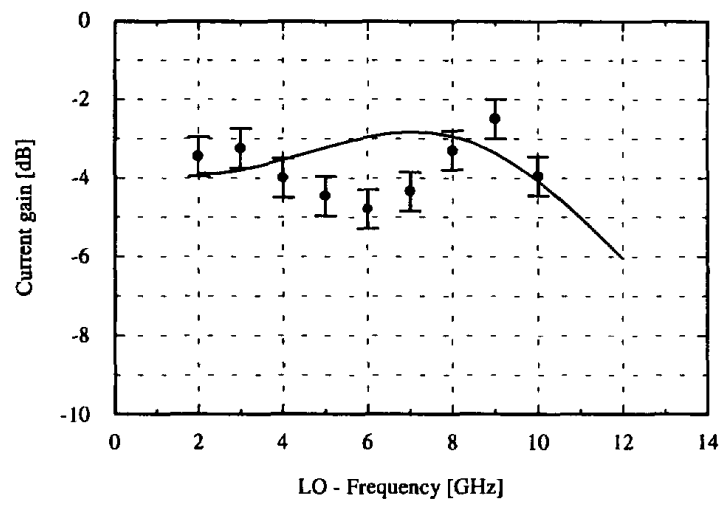

Figure 5: Input bandwidth of the phase detector MMIC in terms of current gain variation. Simulated: Smooth curve, Measured: Dots and error bars. $f_{\mathrm{RF}}=f_{\mathrm{LO}} \pm 100 \mathrm{MHz}, P_{\mathrm{RF}}=-35 \mathrm{dBm}$ and $P_{\text {LO }}=-35 \mathrm{dBm}$.

both the RF- and LO-inputs. An external balun is used to generate the balanced LO-signal, whereas the balanced RF-signal is readily obtained using both photodiode terminals; this significantly reduces the RF-IF time delay.

For the two mixer modules, a low noise dual gate FET mixer configuration has been applied. The upper two FETs of the mixer modules are biased in their saturated region so, that they convert the LOsignal variation to $a V_{d s}$ variation at the lower FET pairs. The bias of the two lower FETs is selected for operation in the knee of the $I_{d s}-V_{d s}$ characteristic. Consequently, the RF-signal will experience both a $g_{\mathrm{m}}$ and $r_{\mathrm{ds}}$ variation in phase with the LO-signal, thus mixing the two signals. Finally, the resulting IF-signal is amplified in the upper FET pairs.

The IF-signals from the drain outputs of the mixer modules add in phase along the virtual IF transmission line and the resulting IF-signal is, finally, amplified by the IF output buffer amplifier. This buffer further provides a high impedance current generator output which is required to optimally drive the CCO-laser of the OPLL.

The symmetrical implementation of the MMIC, as seen from the photo in Fig. 3, has been chosen to maintain the best possible balance of the RF and LO signals. The two mixer modules are seen as the two identical sets of structures in the center of the chip. To minimize the physical size, and thereby the time delay, the incoming transmission lines are connected 
to one side of the FET's gate fingers and the continuation of the transmission lines are carried on from the opposite side of the same gate fingers. This technique also applies to the IF transmission line.

\section{Performance}

For the $\mathrm{O} / \mathrm{E}$ phase detector, the main parameter is the current gain defined as output current injected into the CCO-laser relative to the input RF-current as generated in the photodiode. The implemented phase detector MMIC has been characterized using on-wafer probing. A current gain of $-1.5 \mathrm{~dB}$ with a $3 \mathrm{~dB}$ bandwidth of $2 \mathrm{GHz}$ has been obtained as shown in Fig. 4. This enables application in OPLLs with loop bandwidths of up to $200 \mathrm{MHz}$ [2] Excellent symmetry with respect to $\mathrm{RF}<\mathrm{LO}$ and RF $>$ LO mixing is measured, and the RF-IF time delay has been estimated to $30 \mathrm{ps,} \mathrm{which} \mathrm{is} \mathrm{low}$ compared to the previous bulk implementation with a time delay of around $150 \mathrm{ps}$.

The simulated and measured input bandwidth of the device is shown in Fig. 5 for a fixed offset of $100 \mathrm{MHz}$ between the RF- and LO-signals. Allowing a $1 \mathrm{~dB}$ variation to ensure low phase variation, an input bandwidth of $2-10 \mathrm{GHz}$ is obtained. This secures the microwave signal tunability of the OPLL.

Finally, the damping of higher harmonics is better than $30 \mathrm{~dB}$, the spurious responses are lower than $-70 \mathrm{~dB}$ and the intermodulation products are lower than $-50 \mathrm{~dB}$ at the desired RF-signal level.

\section{Conclusion}

In conclusion, we have presented results on the first integration of an $\mathrm{O} / \mathrm{E}$ phase detector. The results demonstrate that the $\mathrm{O} / \mathrm{E}$ phase detector of wideband OPLLs can be integrated using GaAs MMIC technology yielding a significant performance improvement as compared to nonintegrated versions. This represents the first step toward the complete monolithic opto-electronic integration of semiconductor laser OPLLs.

\section{Acknowledgements}

Part of this work was carried out under ESA, ESTEC contract 122250, and the MMIC was processed through the EuroChip Program.

\section{References}

[1] M. Kourogi et. al.: Photonics Technology Letters, Vol. 3, No. 3, 1991, pp. 270-272.

[2] U. Gliese et. al.: Journal of Lightwave Technology, Vol. 9, No. 6, 1991, pp. 779-790.

[3] R.T. Ramos et. al.: Electronics Letters, Vol. 28, No. 1, 1992, pp. 82-83.

[4] U. Gliese et. al.: Photonics Technology Letters, Vol. 4, No. 8, 1992, pp. 936-938. 